\title{
Inheritance of CMT1A duplication from a mosaic father
}

\author{
E Sorour, P Thompson, J MacMillan, M Upadhyaya
}

\begin{abstract}
We describe a case with molecular duplication of chromosome 17 (p11.2-p12) whose duplicated chromosome was inherited from a mosaic father. The patient has clinical manifestations consistent with Charcot-Marie-Tooth disease type 1A (CMT1A), while the mosaic father has minimal findings of CMT1A. The father was found to be homozygous with DNA markers VAW409R3A (D17S122) and p132G8RI (PMP-22) which are duplicated in CMT1A cases. Fluorescence in situ hybridisation (FISH) analysis with YAC clone $49 \mathrm{H} 7$ confirmed the duplication in the affected patient and diagnosed the mosaicism in his father. These findings based on clinical diagnosis and FISH analysis suggest that the mosaicism may have occurred early in embryogenesis leading to the disease in the father. This is the only reported case of CMT1A with transmission from a mildly affected mosaic father.
\end{abstract}

(f Med Genet 1995;32:483-485)

CMT1A is the most common inherited motor and sensory neuropathy. It is characterised by peroneal muscular atrophy, pes cavus, loss of deep tendon reflexes, and reduced motor nerve conduction velocities. It segregates as an autosomal dominant, fully penetrant phenotype and shows complete linkage with chromosome 17. A large submicroscopic duplication of chromosome band $17 \mathrm{p} 11.2$ associated with CMT1A was originally reported in $1991 .{ }^{12}$ The duplication appears to arise de novo at a relatively high frequency, ${ }^{2-5}$ with the duplicated region spanning about $1.5 \mathrm{Mb}$ and containing at least three $\mathrm{CpG}$ islands, each suggestive of the presence of an expressed gene. ${ }^{6-8}$ Physical mapping ${ }^{6}$ and fluorescence in situ hybridisation (FISH) studies $^{8}$ have shown that the duplication is tandem. The $1.5 \mathrm{Mb}$ region is flanked by a sequence termed CMT1A-REP, which appears to be a complex mosaic repeat of more than $17 \mathrm{~kb}$. It has been proposed that CMT1A-REP might be involved in mediating an unequal crossing over event that leads to the formation of a duplication on one copy of chromosome 17 and a corresponding deletion on the other 17 homologue. ${ }^{6}$ A phenotype associated with the deletion of the same band has recently been identified as hereditary neuropathy with liability to pressure palsies (HNPP). ${ }^{9}$

The finding that peripheral myelin protein 22
(PMP22) is contained within, but not disrupted by the duplication in CMT1A, and the fact that high levels of PMP22 mRNA have been detected only in the peripheral nervous system (the affected tissue in both CMT1A and HNPP), has led to the suggestion that gene dosage may underlie these disorders. ${ }^{1011}$

Molecular analysis of DNA markers at this critical region is the most common technique for diagnosis of duplication; however, in families not informative for these markers and in homozygous sporadic cases, a diagnosis is often difficult. Additionally, such methods would not detect the presence of a duplication in a mosaic patient. FISH analysis using probes within this region offers the potential to resolve these problems.

We report the first instance of mosaicism in CMT1A, where an affected proband has inherited the disease from a mildly affected mosaic father.

\section{Materials and methods} SOUTHERN BLOT ANALYSIS

Genomic DNA was digested with the appropriate restriction enzymes and Southern blot was obtained as previously reported. ${ }^{12}$ DNA probes VAW409R3A(D17S122) and p132G8RI(PMP-22) were labelled with ${ }^{32} \mathrm{P}$ dCTP using primer extension ${ }^{13}$ and hybridised to the blot.

\section{FISH ANALYSIS}

Slides were prepared by standard cytogenetic protocols, and pretreated with RNase and pepsin to optimise the hybridisation. A YAC clone (49H7) which spans the smallest duplication region and includes the PMP22 gene and VAW409 was labelled with Biotin-16-dUTP (Boehringer) by a nick translation kit (Gibco BRL). After separation of the labelled probe using Sephadex G-50 spin column, $250 \mathrm{ng}$ of the probe and $300 \mathrm{ng} \operatorname{Cot} \mathrm{I}$ DNA were added to a hybridisation mix consisting of $50 \%$ formamide, $20 \%$ dextran sulphate, and $2 \times$ SSCP. The mixture was denatured at $80^{\circ} \mathrm{C}$ for 10 minutes and preincubated for 20 minutes at $37^{\circ} \mathrm{C}$. The slides were denatured separately at $80^{\circ} \mathrm{C}$ for four minutes. Hybridisation was overnight at $37^{\circ} \mathrm{C}$ in a humidified chamber. Analysis of 125 interphase nuclei from the proband, his father, and a normal control was performed by counting the hybridisation signals per nucleus. Blood samples were not available from other members of the family. 


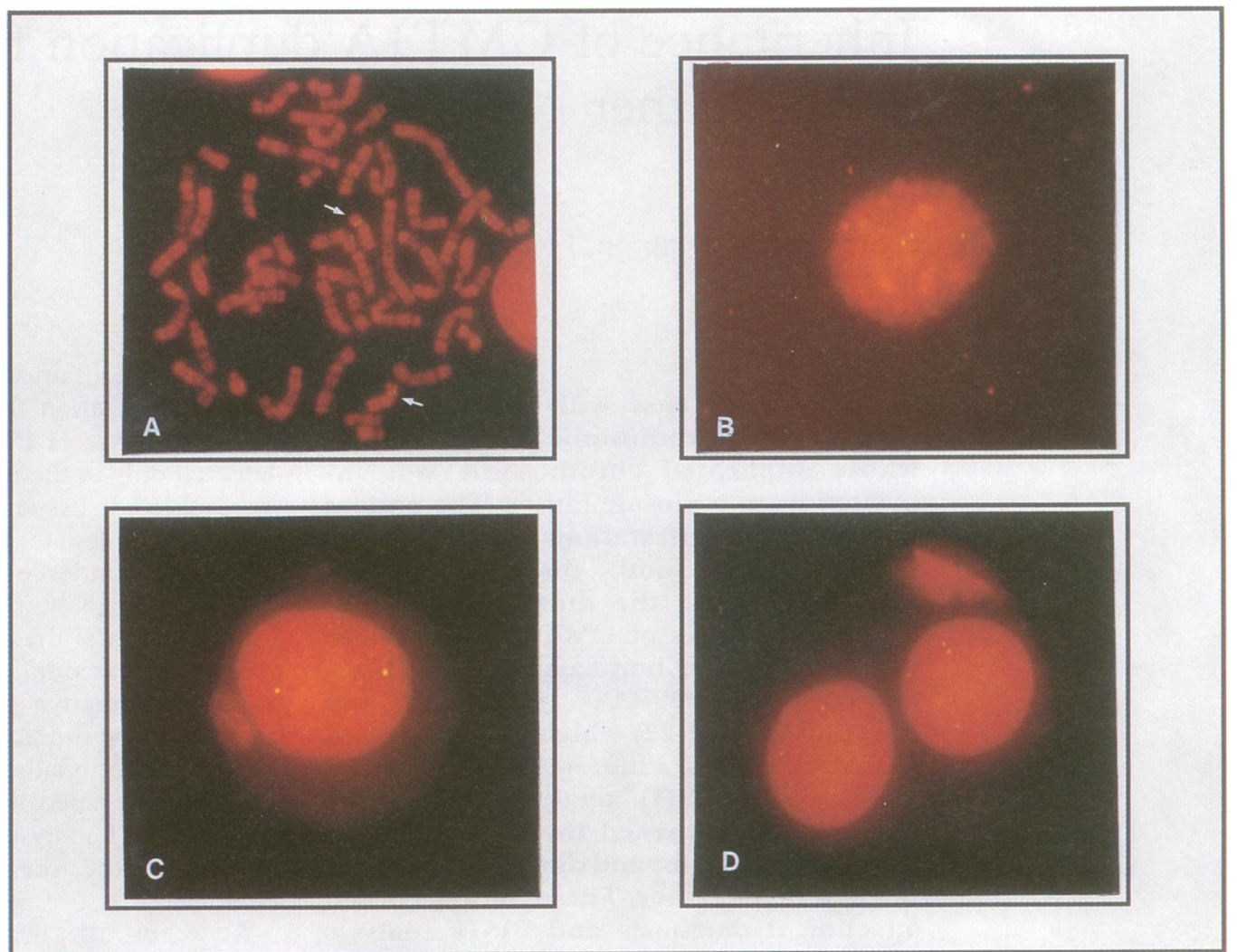

Figure 1 Hybridisation of $Y 49 H 7$ in the mosaic father. (A) Hybridisation to chromosome $17 p$ in an $R$ banded metaphase spread, $(B)$ duplication of signal in an interphase nucleus, $(C)$ normal signals in an interphase nucleus, (D) normal and duplicated signals.

\section{Results}

CLINICAL REPORT

The proband developed distal lower limb weakness at 10 years, and at the age of 19 required a right ankle arthrodesis. He noted some diminution in sensation in the feet but denied weakness or sensory loss in the upper limbs. $\mathrm{He}$ had a significant degree of bilateral sensorineural deafness. On examination his speech was slightly dysarthric and apart from his deafness his cranial nerves were normal. In the limbs there was no tremor, he had mild bilateral weakness of the intrinsic muscles of the hands, and marked weakness of ankle dorsiflexion. The ankle jerks were absent but knee jerks and all upper limb tendon reflexes were normal. Sensory loss was most marked in the feet and he had a painless ulcer over the head of the

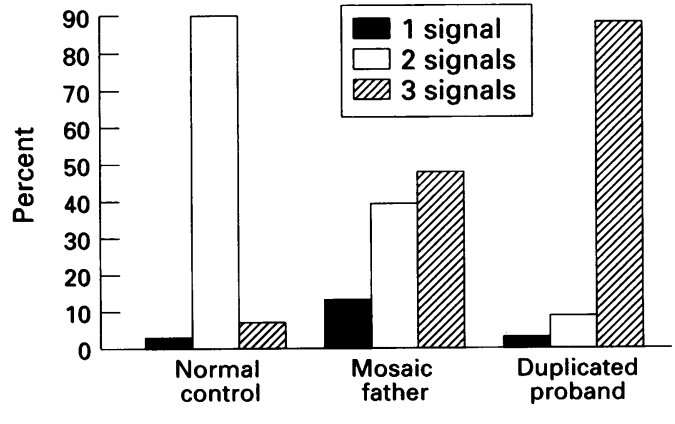

Number of signals in interphases

Figure 2 The percentage signal in 125 nuclei by FISH analysis using probe Y49H7 in the proband, his father, and a normal control. first left metatarsal. He had bilateral pes planus, clawing of the toes, and palpable enlargement of the common peroneal nerves. Electrophysiologically, the median motor nerve conduction velocity was $33 \mathrm{~m} / \mathrm{second}$, the median sensory action potential (MSAP) was $5 \mu \mathrm{V}$, and the ulnar sensory action potential (USAP) was $2 \mu \mathrm{V}$. His lateral popliteal motor conduction could not be measured as extensor digitorum brevis was denervated. His father had clawing of the toes from childhood and had been noted to be clumsy.

However, he was aware of increasing unsteadiness of gait from the age of 40 and some difficulty with coordination in the upper limbs from the age of 50 . Neurological examination did not show any weakness in the lower limbs and all his tendon reflexes were intact. $\mathrm{He}$ had minimal sensory impairment in the feet, and had bilateral pes planus. Electrophysiological examination showed a normal median motor conduction velocity ( $54 \mathrm{~m} / \mathrm{second})$, a mild drop of the ulnar conduction velocity ( $46 \mathrm{~m} / \mathrm{second}$ ), and a significant slow sural sensory nerve conduction velocity ( $22 \mathrm{~m} / \mathrm{second}$ ). His ulnar sensory action potential was absent, and his median sensory action potential was $6 \mu \mathrm{V}$.

\section{SOUTHERN BLOT ANALYSIS}

The proband and his parents were homozygous for allele 1 with probe p132G8RI. However, with probe VAW409R3A the proband had two copies of allele 2 and one copy of allele 1 , his father was homozygous for allele 2 , while his mother was homozygous for allele 1 . 
FISH ANALYSIS

Analysis of $\mathrm{R}$ banded metaphases of the normal control showed that the YAC clone $49 \mathrm{H} 7$ mapped to the CMT1A specific region (17p11.2-p12). Fig 1 shows hybridisation of $\mathrm{Y} 49 \mathrm{H} 7$ in the mosaic father. FISH analysis of interphases from a normal control showed the following distribution of signals: one signal in $3.5 \%$ of nuclei, two signals in $90 \%$, and three signals in $6.5 \%$. A comparative FISH analysis of a normal control, the mosaic father, and the duplicated patient is illustrated in fig 2 .

\section{Discussion}

The use of FISH with the YAC clone $49 \mathrm{H} 7$ that lies within the duplicated region in CMT1A has resulted in the detection of a mosaic case for this disorder. A mildly affected father of an affected son with CMT1A was shown to have a duplication of $17 \mathrm{p}$ in $47.6 \%$ of interphase nuclei examined from peripheral blood. The mutation event most likely arose de novo during early embryonic development owing to misalignment of the sister chromatids of one chromosome 17, which can result in unequal crossing over, leading to duplicated progeny in the father. The Southern blot analysis with probe VAW409R3A in this family has clearly suggested that the proband had inherited two copies from the father and one copy from the mother. These results indicate that the proband is unlikely to have a de novo duplication. The new mutations for CMT1A duplication appear to be predominantly of paternal origin. ${ }^{25}$ The mechanism that underlies this mutation, in contrast to the present case, might be unequal non-sister chromatid exchange during spermatogenesis.

Examination of the proband's father showed minimal clinical findings. His electrophysiological findings are clearly abnormal in sural sensory and ulnar motor conduction but within normal limits of median motor conduction. This clinical picture will fit in with his being a mosaic.

Somatic mosaicism is an important cause of phenotype modification resulting in variation in the clinical expression of an inherited trait or disorder, ${ }^{11}$ with the proportion of affected cells in the expressing tissue(s) of the person concerned clearly being an important factor in determining phenotypic severity. Mosaicism for a specific gene mutation may be confined to somatic cells or the germline, or be present in both, depending on the developmental stage at which the lesion occurred. Germline mosaicism provides an explanation for the inheritance pattern in cases where multiple affected offspring are born to clinically and phenotypically normal parents. Moreover, if the germline of an affected subject is also involved, subsequent progeny may be at risk of developing a much more severe phenotype, for example, as in cases of osteogenesis imperfecta and Smith-Magenis syndrome. ${ }^{1415}$

The possibility of undetected mosaicism has been suggested in a CMT1 family. ${ }^{16}$ Mosaicism for deletion within this region of chromosome 17 has been previously reported. ${ }^{15}$ In this family, the mildly affected mother of a proband with Smith-Magenis syndrome associated with a visible deletion of $17 \mathrm{p} 11.2-\mathrm{p} 12$ was also found to have the deletion in $55 \%$ of cells examined. Our findings show the potential importance of using FISH as a first line diagnostic test for CMT1A, and at present the technique would appear to be the only way of detecting mosaicism in the disease. The result also raises the issue of whether parents of sporadic CMT1A cases should be tested by FISH to exclude the possiblity of mosaicism.

The authors are grateful to M Osborn for technical assistance and to the Medical Research Council (MRC) for financial support.

1 Lupski JR, De Oca-Luna RM, Slaugenhaupt S, et al. DNA duplication associated with Charcot-Marie-Tooth disease type 1A. Cell 1991;66:219-32.

2 Raeymaekers P, Timmerman V, Nelis E, et al. Duplication in chromosome 17p11.2 in Charcot-Marie-Tooth neuropathy type 1a (CMT 1a). Neuromusc Dis 1991;1:93-7.

3 Hoogendijk JE, Hensels GW, Gabreels-Festen AAWM, et al. De-novo mutation in hereditary motor and sensory neuropathy type 1. Lancet 1992;339:1081-2.

4 Wise CA, Garcia CA, Davis SN, et al. Molecular analysis of unrelated Charcot-Marie-Tooth (CMT) disease patients unrelated Charcot-Marie-Tooth (CMT) disease patients suggest a high frequency of the
7 Hum Genet 1993;53:853-63.

5 Palau F, Lofgren A, De Jonghe P, et al. Origin of the de novo duplication in Charcot-Marie-Tooth disease type 1A: unequal nonsister chromatid exchange during spermatogenesis. Hum Mol Genet 1993;2:2031-5.

6 Pentao L, Wise CA, Chinault AC, et al. Charcot-MarieTooth type $1 \mathrm{~A}$ duplication appears to arise from recombination at repeat sequences flanking the $1.5 \mathrm{M}$ monomer unit. Nature Genet 1992;2:292-300.

7 Hoogendijk JE, Hensels GW, Zorn I, et al. The duplication in Charcot-Marie-Tooth disease type 1A spans at least $1100 \mathrm{~kb}$ on chromosome 17p11.2. Hum Genet 1991;88: 215-18.

8 Valentijn LJ, Bolhuis PA, Zorn I, et al. The peripheral myelin gene PMP22/GAS-3 is duplicated in Charcot-MarieTooth disease type 1A. Nature Genet 1992;1:166-70.

9 Ċhance PF, Bird TD, O'Connell P, et al. DNA deletion associated with hereditary neuropathy with liability to associated with hereditary neuropathy

10 Patel PI, Roa BB, Welcher AA, et al. The gene for the peripheral myelin protein PMP-22 is a candidate for peripheral myelin protein PMP-22 is a candidate for 1:159-65.

11 Hall JG. Somatic mosaicism: observations related to clinical genetics. Am $\mathcal{F}$ Hum Genet 1988;43:355-63.

12 Upadhyaya $M$, Shen $M$, Cherryson A, et al. Analysis of mutations at the neurofibromatosis 1 (NF1) locus. Hum Mol Genet 1992;1:735-40.

13 Feinberg AP, Vogelstein BA. A technique of radiolabelling DNA restriction endonuclease fragments to high specific activities. Anal Biochem 1983;132:6-13.

14 Byers PH, Tsipouras P, Bonadio JF, et al. Perinatal lethal osteogenesis imperfecta (OI type II): a biochemically heterogeneous disorder usually due to new mutation in the genes for type 1 collagen. Am $\mathcal{f}$ Hum Genet 1988;42: 237-48.

15 Zori RT, Lupski JR, Heju Z, et al. Clinical, cytogenetic, and molecular evidence for an infant with Smith-Magenis syndrome born from a mother having a mosaic $17 \mathrm{p} 11.2 \mathrm{p} 12$ deletion. Am f Med Genet 1993;47:504-11.

16 Ionesascu VV, Ionesascu R, Searby C, Baker DF. CharcotMarie-Tooth neuropathy type $1 \mathrm{~A}$ with both duplication Marie-Tooth neuropathy type 1A with both duplication
and non-duplication. Hum Mol Genet 1993;2:405-10. 